\title{
Facilitating Integrated Coastal Zone Management in Trinidad
}

\author{
Natasha Carpenter, Royal Haskoning, n.carpenter@royalhaskoning.com \\ Tamzen Strudwick, Royal Haskoning, t.strudwick@royalhaskoning.com \\ Victoria Clipsham, Royal Haskoning, v.clipsham@royalhaskoning.com
}

\begin{abstract}
Trinidad is the southernmost of the Caribbean Islands and is classified as a Small Island Developing State (SIDS). These States are prone to specific social, economic and environmental vulnerabilities.
\end{abstract}

Trinidad's coastline supports a number of communities and a range of infrastructure including the coastal road, fishing facilities and ports, along with oil and gas facilities. Furthermore, the potential for eco-tourism should not be overlooked considering the aesthetic value of its beaches and their importance for Leatherback turtle nesting.

However, a number of coastal management issues are present along the frontage, including the imminent failure of the north-east coastal road at several locations. This threatens the socioeconomic continuity of the coastline and poses a risk to public safety. As such, the island requires a balance between imminent, hard engineering schemes and long term, sustainable and holistic coastal zone management.

In order to recognise the importance of this, Royal Haskoning hosted a Coastal Zone Management Workshop. This included representatives from various Ministries within the Government of Trinidad and Tobago and provided an opportunity to assess the current institutional structure of the island. Through this exercise it was possible to make recommendations towards methods to facilitate this management approach. As such, this paper elaborates upon the key findings, including the issues being experienced on the coastal frontage and the current institutional arrangement of the island in terms of delivering coastal projects. This is underpinned by a robust geomorphological understanding of the area and concludes with a series of recommendations towards its improvement through capacity building.

Keywords: Capacity Building, ICZM, Coastal Infrastructure

\subsection{Introduction}

Trinidad is the southernmost of the Caribbean Islands and is situated between 10 and 11 degrees north of the equator. As a result of its geographical location, it just misses the hurricane belt. However, north-east trade winds dominate the island and expose the frontage to strong wave action and in turn erosion. This is placing significant pressure on the coastal frontage of the island.

Along with these governing north-easterly processes, the frontage is also susceptible to infrequent but severe north-westerly storms. These provide a dramatic contrast to the prevailing conditions, with the juxtaposition of energy causing an increased vulnerability. 
Effective responses to these pressures are hindered by Trinidad's position as a Small Island Developing State (United Nations, 2010). Significant investment is being made in the development of Trinidad's infrastructure, however, as is seen in many other countries where coastal projects are delivered on an isolated basis, there is a lack of coherence between objectives and what infrastructure is trying to achieve.

One of the key areas experiencing issues along the coastline is on the north-east coast. This frontage can be considered rural but a number of communities are linked by a coastal road. However, as a result of the exposed and steep nature of this frontage the road is at risk at a number of locations, potentially compromising the socio-economic continuity of the frontage.

In response to this, the Ministry of Works and Transport (MOWT) and the National InfrastructureDevelopment Company (NIDCO) commissioned a Coastal Protection Works Study for the frontage. The overall aim of which was to determine the feasibility and to prepare final designs, for a series of coastal intervention works to protect the frontage from the key issues of erosion, flooding and slope instability. In fulfilling this, the need to fully understand the issues being experienced and their connections with maintaining the socio-economic continuity of the area was recognised.

\subsection{Characterisation of the Study Frontage}

The study frontage extends approximately $50 \mathrm{~km}$, from Fillette Point in the west, to Galera Point in the east. It is predominantly backed by rising land, with a general cliffed backshore of varying height, formed along the foothills of the Northern Mountain Range. This is interspersed with lower lying bays, where the main rivers cut the coast forming valleys into the hinterland. Within these more major bays, sediment infill has tended to develop as a full barrier beach ridge, forming the principle protection to the lower lying land of the valley behind. In other areas, not associated with the main rivers but where there has been differential erosion, narrow beaches have formed where beach sediment is held by local headlands. These narrower beach sections tend to be formed as enclosed coves or crenulated shaped bays, each fronting directly onto the cliffed or artificially defended backshore.

The geology of the frontage has a strong influence on its coastal geomorphology, allowing formation of the headlands and bays. It comprises primarily of low-grade metamorphic rocks of varying strength and erosion resistance, both over substantial lengths of the coast but also at a very local scale. There are also areas of overlying clays and loosely bound sedimentary rock, allowing zones of differential erosion. In addition, there are quite extensive intrusions of harder igneous rock forming headlands.

\subsection{Key Issues}

Along the study frontage an array of coastal issues and socio-economic vulnerabilities can be identified as summarised in Figure 1 and the following text. 


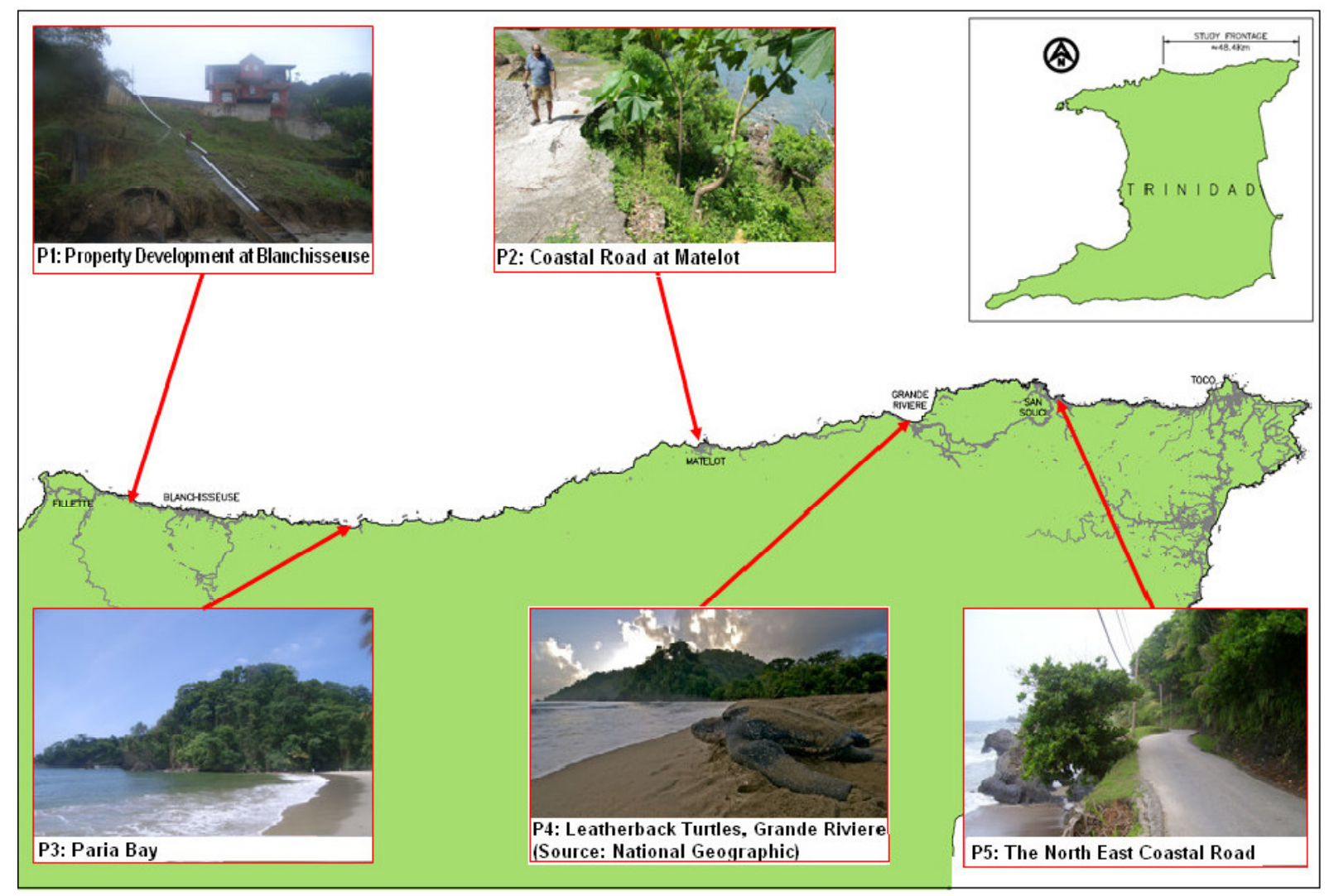

Fig. 1. Overview of the Study Frontage and Key Issues

The village of Blanchisseuse (P1) is situated to the west of the study frontage; here the key issue is the presence of a relatively large community located on the steep coastal slopes of the Northern Mountain Range. As a result, the village and the associated access road are susceptible to erosion and slope instability; this is further exacerbated by unauthorised property development along the frontage which presents a coastal planning issue. Similarly, the village of Matelot (P2) in the centre of the study frontage can only be accessed via one road which is situated on the edge of the coastline. However, poor access from the village has hindered its development with a decline in agricultural trade, leaving its fishing facility as its primary source of income. Furthermore, the potential failure of the coastal road threatens isolation of the community.

In contrast to these rural communities, a number of areas along the frontage are prized for their potential value towards eco-tourism. The rural frontage of Paria (P3) is not connected by the coastal road but is a popular hiking destination whilst the beach of Grande Riviere (P4) is one of the world's most important Leatherback Turtle nesting sites.

The latter hosts more than 5,000 turtles per season and subsequently is one of the most visited turtle beaches in the world, attracting up to 15,000 visitors a year (National Geographic, 2010). As such it is important to preserve the natural character and ecological value of both areas, supporting development to promote tourism but in a manner which will not spoil the region or become unsustainable as a result of coastal erosion or tidal/fluvial inundation. 
Beach management is also an important objective along the frontage. The bays of San Souci and Salybia are both popular areas for recreation. They are also popular areas for development but this is commonly unregulated and unsustainable, with risks of coastal erosion and flooding. In response to this, the provision of localised defences are interrupting the natural processes governing these areas.

In all instances, one of the consistent issues across the frontage is management of the coastal road. This is critical infrastructure, linking together the various communities, residential and commercial developments, fishing facilities and hotspots for eco-tourism. As such, maintaining its integrity is of utmost importance but is recognised as being compromised at a number of sections, with issues of coastal erosion, slope instability, overtopping, and undermining being experienced throughout the frontage.

\subsection{Methodology}

The Coast Protection Works Study provided a crucial understanding of the coastal processes influencing the study site and the associated issues. Within the study the clear need for management, drawing together the various sociological and physiological aspects was recognised. As such, a Coastal Zone Management Workshop was hosted within the study, to educate policy makers and raise awareness of methods to facilitate Integrated Coastal Zone Management (ICZM).

The Workshop included 24 delegates who were selected to represent key decision makers and stakeholders in the islands' coastal zone. This included members of the various Ministries of the Government of Trinidad and Tobago, the Environmental Management Authority (EMA), Institute of Marine Affairs (IMA), Town and Country Planning and the Water and Sewerage Authority (WASA). The key aims of the workshop were to:

- Discuss the current implementation process of coastal projects;

- Develop appropriate institutional recommendations to promote effective management of the coastal zone, including the development of a coastal management plan and monitoring and maintenance schemes; and

- Formulate particular recommendations for the establishment of a responsible coastal management unit.

In order to meet the aims of the workshop, a series of exercises were undertaken. In particular, delegates were divided into four groups to decide upon a hypothetical project to be implemented on a specific section of the frontage. Projects considered included the potential upgrading of a fishing facility and construction of coastal intervention works.

During the Workshop the groups were tasked with mapping out the current institutional set-up of the country, to outline how delegates believed that their hypothetical project would currently be implemented 'on the ground'. The aim of which was to highlight the need for an institutional reform to provide a fundamental building block towards the promotion of ICZM on the Island.

\subsection{Results}

The workshop identified a generic institutional structure of the Government of Trinidad and Tobago, with respect to delivering coastal schemes on the Island, as summarised in Figure 2. 


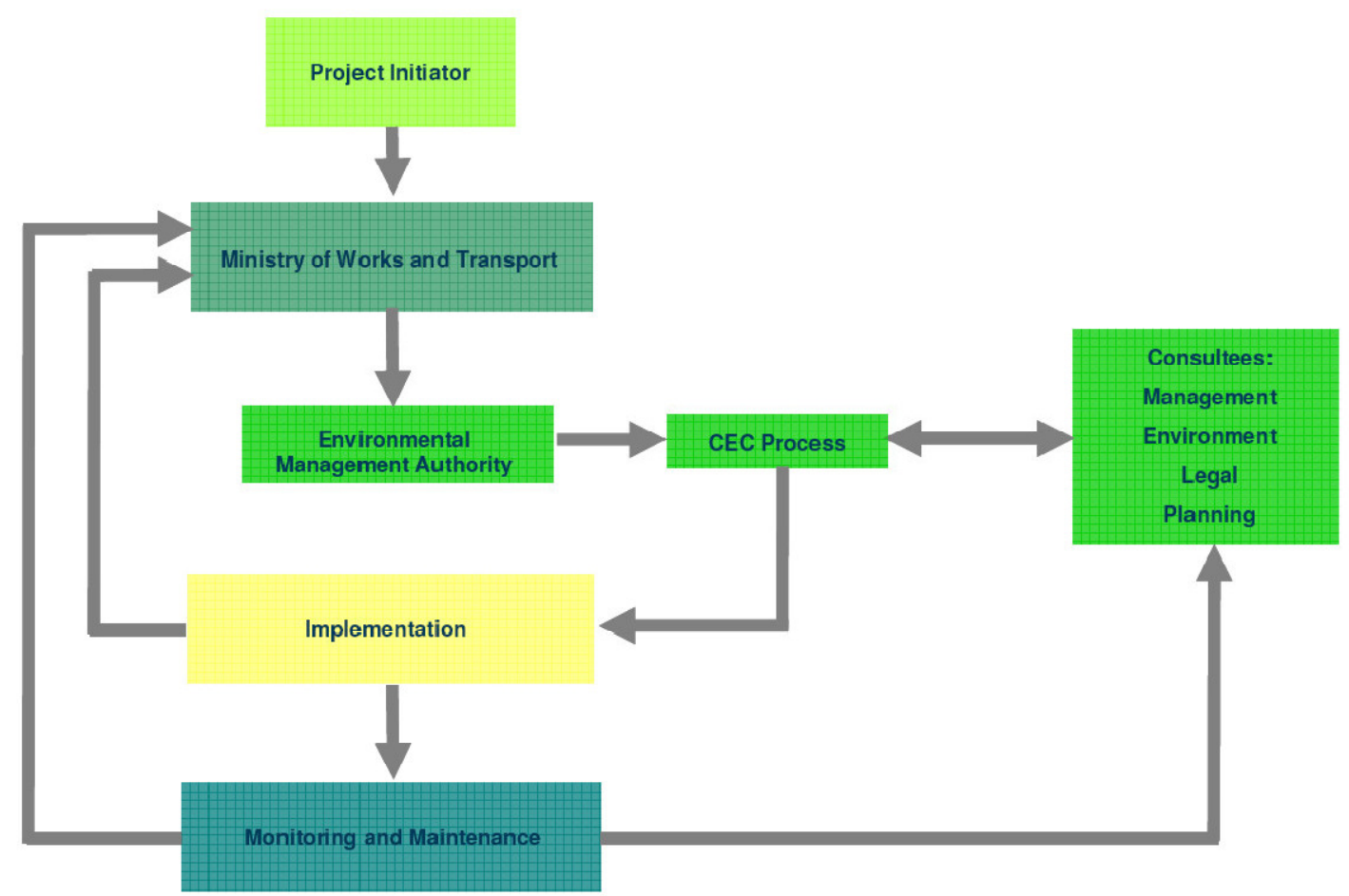

Fig. 2. Project Implementation in Trinidad and Tobago

The Figure outlines a complex delivery process, which involves a range of different Ministries and Organisations, particularly during the consultation process. In general it was agreed that the MOWT commonly take the lead on coastal intervention projects. They will contact the EMA to gain approval for projects and this will require the production of a Certificate of Environmental Clearance (CEC). This process involves consultation with a number of stakeholders and Government Ministries and potentially the production of an Environmental Impact Assessment (EIA).

Upon approval of the coastal intervention works, the project is implemented, and again is often undertaken by the MOWT. Responsibilities of monitoring and maintenance works after the scheme is completed remain unclear and it was noted that this process is commonly not undertaken due to a lack of available funds.

The exercises undertaken demonstrated the unstructured nature and complexity of the project implementation process. A significant lack of coordination between the relevant Ministries, Organisations and Institutes, that all have a stake in the coastal zone, was strongly recognised. This can hinder the delivery process as a result of a lack of responsibility between the various stakeholders or duplication of elements as a result of uncoordinated actions. Developing from the workshop was an awareness that there was a lack of ownership of the coastal zone which was not previously apparent. As such, the workshop highlighted that in order to understand the local scale problems affecting the frontage, it is first necessary to recognize the broader scale management issues.

\subsection{Discussion and Recommendations}


The results of the workshop highlighted the need for a more holistic approach to facilitate ICZM on the island and that this must be supported by institutional change from the delegates. In response to this a series of good practice recommendations were made to the Government of Trinidad and Tobago, these are outlined in the following sub-sections.

\subsection{Coastal Management Unit}

Considering the incoherent nature of the current institutional arrangement of the island, the first recommendation from the workshop was the establishment of a responsible Coastal Management Unit (CMU). The overall aim of the CMU should be to design and implement an island wide ICZM Plan, along with taking responsibility for coastal monitoring, data collection research and coastal planning. It is envisaged that the CMU can ensure the correct balance is maintained between the economic, social and physical features of the coastline.

It is intended that the CMU will be proactive and responsible for initiating coastal projects identified within its own coastal management plan (CMP). It is essential that the Unit work with project initiators to ensure that any new projects, that are outside the scope of the plan, are approved to fit in with the overall vision of the coastline, considering their sustainability and impacts on the frontage.

Considering the Islands' complex institutional arrangements, it was recommended that the CMU is established within an existing Government Ministry which will ease the foundation process. The Unit should consist of a Steering Group and a Board of Representatives. The Steering Group would be responsible for setting out the long term objectives for coastal management in Trinidad and Tobago and developing the CMP. In order to undertake this in a holistic and sensitive manner, the Steering Group has to include a wide range of Ministries and Organisations, as outlined in Figure 3.
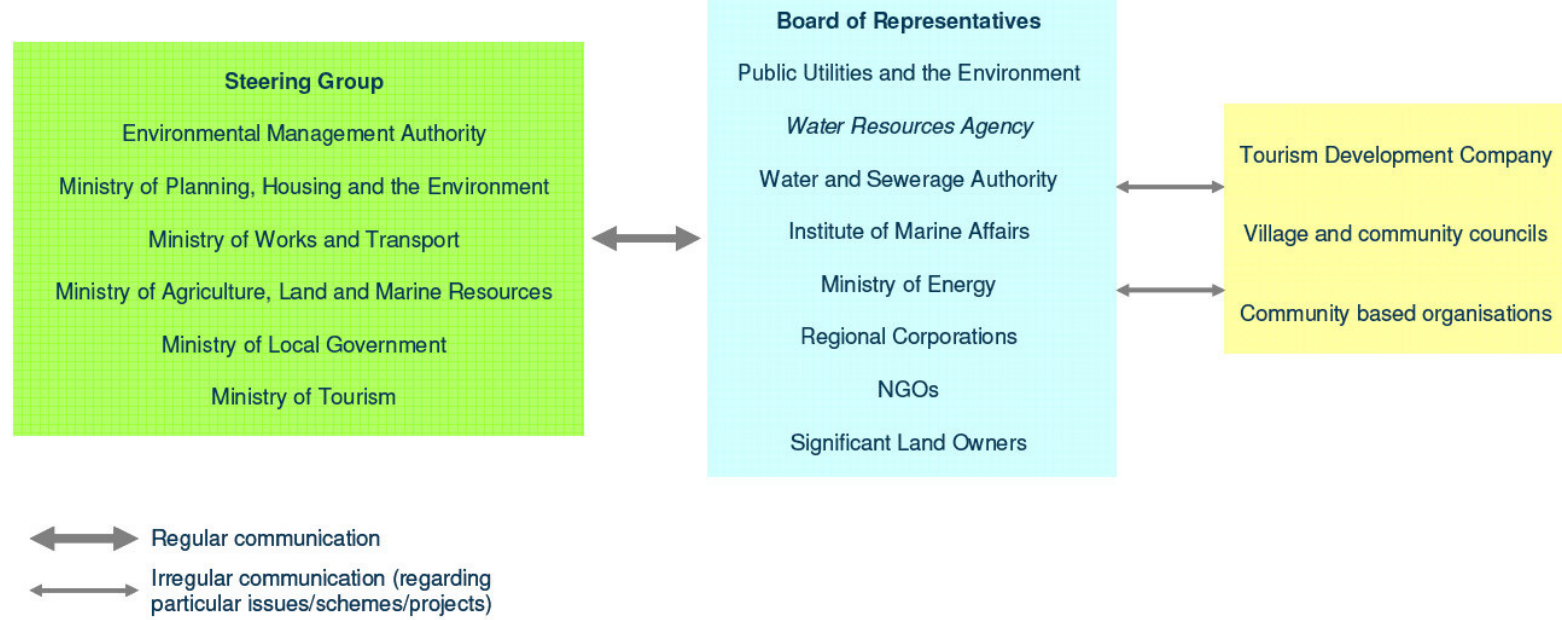

\section{Fig. 3. Coastal Management Unit Organogram}

A Board of Representatives should also be established within the CMU. Their role is to act as Stakeholders and subsequently ensure that a feedback process is undertaken. The Board would have no direct responsibility regarding the establishment of the CMP, but instead would be involved in the process to provide specific input based upon their particular mandates. Owing to the more localised nature of the Board, it is envisaged they would consult directly with the 
Tourism Development Company, villages and community councils and local organisations, as outlined in Figure 3.

\subsection{Improving Delivery of Coastal Projects}

Upon the establishment of a responsible Coastal Management Unit, Figure 4 outlines how this would modify the current implementation structure.

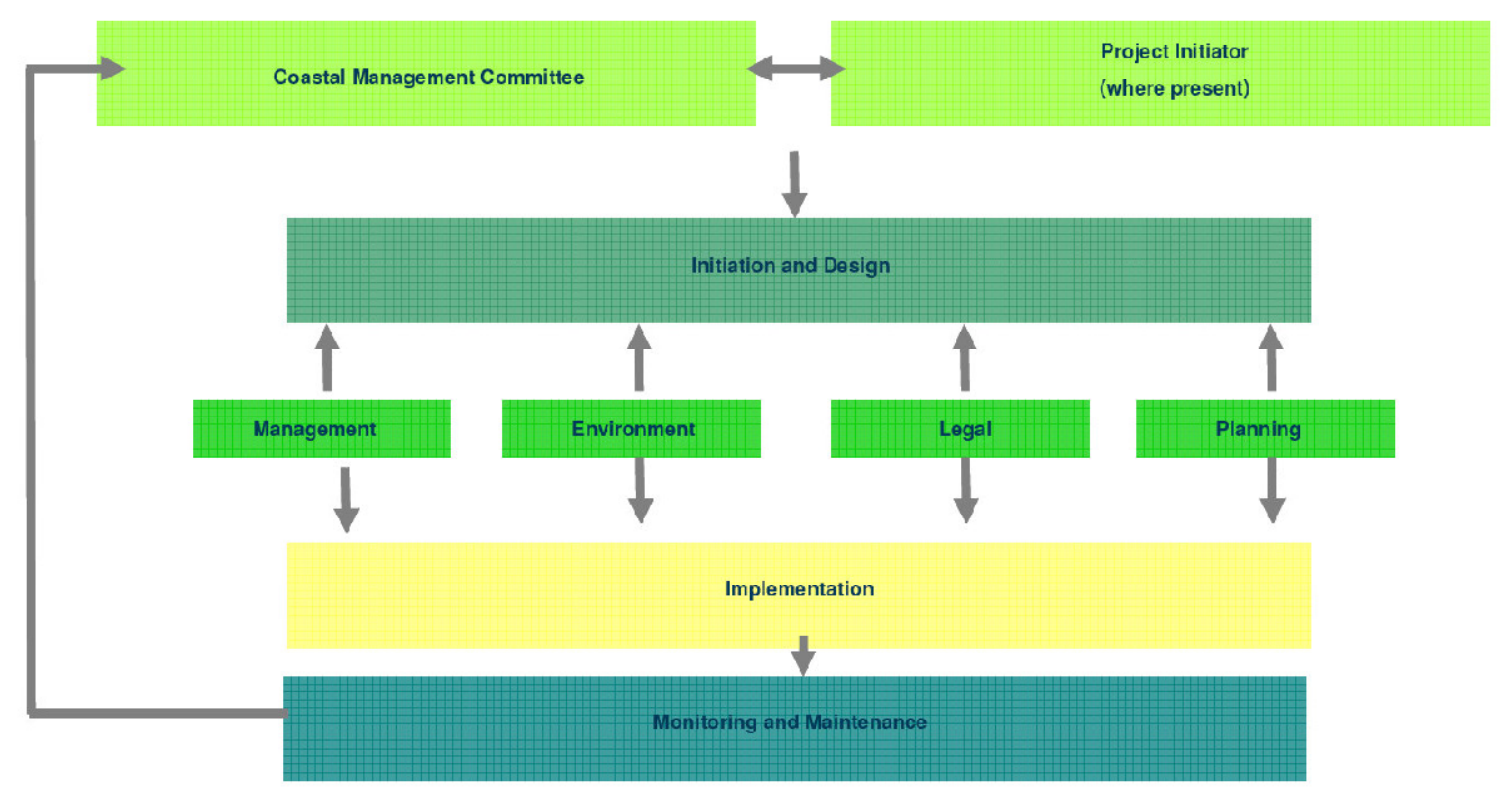

Fig.4. Revised Project Implementation in Trinidad and Tobago under Coastal Management Unit

The revised process shows that the Project Initiator will now approach the CMU with any requests to implement a coastal project. This will ensure that projects are approved through consideration of an agreed framework (CMP) which falls under their responsibility. Upon approval of the project, it can proceed to the implementation between both the project initiator and the CMU.

Considering the members of the Steering Group and the Board of Representatives, which will include representatives of relevant Ministries and Organisations, it is believed that the approval and consultation process will be streamlined and subsequently more effective. This process is represented in Figure 4 by the double arrows. Following approval and implementation, it is vital that monitoring and maintenance works are undertaken and continued. This will provide an opportunity to assess the effectiveness of the works and identify any issues which may affect the lifetime of a structure or development. For consistency, this process should be led by the $\mathrm{CMU}$ who will have the overall responsibility for data collection on the island.

\subsection{Evaluation}

The key aim of the Workshop was to highlight the current institutional structure of the island and the need for institutional reform to facilitate ICZM through capacity building. Whilst this has been achieved, it is acknowledged that this has only formed the initial step in this process and as such there are a number of future actions which are required to enable the continued development of island wide coastal management, which can respond to the local scale coastal 
issues (such as those identified on the north-east coast) but within the context of the wider coastal zone.

A major constraint identified within the Workshop is funding. A lack of financial support has the potential to be a major inhibitor to the establishment of the CMU, development of an island wide CMP and investment in schemes, data collection and monitoring activities. However, it is essential that this does not become a barrier to the process but that instead a phased implementation approach is considered and potential funding mechanisms are explored. Furthermore, considering the range of high priority sites identified across the frontage, it may be acceptable to initially consider the development of specific, reactive, coastal defence plans to identify areas of high risk which require immediate intervention. This will leave the potential to build into a comprehensive, integrated plan in the future.

It is also recognised that legislation is required to support the establishment of the CMU and its key objectives. Three forms of legislation are recognised as relevant towards this in Trinidad and Tobago; The Institute of Marine Affairs Act (1976); The Territorial Sea Act (1969), and; The Environmental Management Act (1995). However, the current format of these laws limits their application and it is therefore recommended that a bespoke 'Coastal Management Act' is founded. This must be a fully functional element of the Government of Trinidad and Tobago and practiced by the CMU to ensure it is adhered to.

\subsection{Conclusions}

The Coast Protection Works Study for the north-east coast of Trinidad has highlighted the vulnerable nature of the coastal zone and its important interrelation with the local community. As part of this study, the Coastal Management Workshop has highlighted the current barriers towards the establishment of effective ICZM on the Island.

In particular, the need for institutional reform is acknowledged. This will have a key role in facilitating ICZM, bringing together the key stakeholders in the coastal zone to form a responsible unit to; regulate development of the frontage; improve the delivery of coastal projects; and, collect appropriate monitoring data. In order for this process to be effective, it is important it is supported by associated legislation and that funding mechanisms are explored to ensure its future development.

\subsection{Acknowledgements}

This work was carried out under the 'Coastal Protection Works at Blanchisseuse, Matelot, Grande Riviere, San Souci and Toco Study', which was commissioned by the Ministry of Works and Transport and the National Infrastructure Development Company. As such, we would like to thank the Government and Trinidad and Tobago for undertaking this study, the delegates whom attended the Coastal Management Workshop, the University of the West Indies and the local residents who all have made valuable contributions towards this study.

\subsection{Literature Cited}

National Geographic. 2010. See Turtles: Grande Riviere, [online]. Available at: < http://www.seeturtles.org/886/grande-riviere.html> [Accessed 22 April 2010].

United Nations. 2010. List of Small Island Developing States, [online]. Available at: < http://www.un.org/special-rep/ohrlls/sid/list.htm> [Accessed 30 March 2010]. 